\title{
Characterization of Mycorrhizal Isolates of Rhizoctonia solani from an Orchid, Including AG-12, a New Anastomosis Group
}

\author{
D. E. Carling, E. J. Pope, K. A. Brainard, and D. A. Carter
}

First and third authors: University of Alaska Fairbanks, 533 E. Fireweed, Palmer 99645; and second and fourth authors: Department of Microbiology, University of Sydney, Australia, 2006.

Accepted for publication 29 June 1999.

\begin{abstract}
Carling, D. E., Pope, E. J., Brainard, K. A., and Carter, D. A. 1999. Characterization of mycorrhizal isolates of Rhizoctonia solani from an orchid, including AG-12, a new anastomosis group. Phytopathology 89:942-946.

Isolates of Rhizoctonia solani collected from mycorrhizal orchid (Pterostylis acuminata) plants and adjacent leaf litter were characterized. Of 23 selected isolates, 20 were members of a new anastomosis group (AG-12) and the rest were members of AG-6. There were no bridging anastomosis reactions observed between AG-12 and other AGs of $R$. solani. Among the 20 isolates of AG-12 evaluated, 18 vegetatively compatible popula-

tions were detected, indicating diversity within the AG. Mature cultures were dark brown, as were mature sclerotia. Some cultures produced alternating dark- and light-colored concentric rings, with sclerotia forming in the darker rings. Most cultures were appressed to the agar surface. In tests run to characterize pathogenic potential, selected mycorrhizal isolates of AG-12 and AG-6 did little damage to potato and barley seedlings, moderate damage to head lettuce seedlings, and more extensive damage to seedlings of cauliflower and radish. Isolates of AG-12 have not been observed to fruit in nature, and all attempts to induce formation of the teleomorph (Thanatephorus cucumeris) in the laboratory by selected isolates of AG-12 failed.
\end{abstract}

Rhizoctonia solani Kühn, also known by the genus name Moniliopsis Rhuland (19,31) (teleomorph Thanatephorus cucumeris (A.B. Frank) Donk), is a widely distributed, largely soilborne plant parasitic-saprophytic fungus. Its characterization as a collective species $(1,3)$ is based on its containing many related but genetically isolated groups. These genetically isolated groups within $R$. solani often are identified on the basis of hyphal anastomosis reactions $(3,6,20,21)$, although other techniques for grouping isolates also can be used $(1,11)$. Hyphal anastomosis in $R$. solani is a vegetative incompatibility reaction that develops to differing degrees between confronted isolates depending on the relatedness of paired isolates. Distantly related isolates show no anastomosis reaction, whereas walls, membranes, and cytoplasm of clonal isolates fuse (6). Twelve anastomosis groups (AGs) have been described $(6,10$, 20,21), and many of these AGs have been subdivided on the basis of physical, chemical, or molecular characteristics $(1,14,21,26)$.

All orchids are mycorrhizal (4), and the fungal participants in many of these associations are members of the genus Rhizoctonia. Most of the Rhizoctonia known to participate in mycorrhizal relationships with orchid are binucleate with a Ceratobasidium teleomorph. However, though comparatively infrequent, multinucleate Rhizoctonia also have been isolated from mycorrhizal orchids $(12,24$, $28,29,31)$. Sometimes, these multinucleate mycorrhizal isolates have been induced to form a Thanatephorus teleomorph $(12,28,31)$.

Perkins and McGee (23) collected isolates of $R$. solani, initially identified as members of AG-6, from adult plants or protocorms of Pterostylis acuminata $\mathrm{R}$. Br. growing at a study site or in other natural bush settings in and around Sydney, Australia. More recently, E. J. Pope (unpublished data) collected isolates of $R$. solani from additional bush sites in the same general area. In both studies, isolates also were collected from leaf litter adjacent to the mycorrhizal plants. A closer examination of part of these collections revealed that many isolates would not anastomose with testers of any

Corresponding author: D. E. Carling; E-mail address: pfdec@uaa.alaska.edu

Publication no. P-1999-0818-01R

(C) 1999 The American Phytopathological Society known AG. We propose to call this new group AG-12 and will characterize it further in this article.

\section{MATERIALS AND METHODS}

Collection and isolation. Tester isolates used in anastomosis studies and representing all of the known AGs of $R$. solani, as well as most of their subgroups, are listed in Table 1. Isolates used in one or more of the other characterization studies, including mycorrhizal isolates of AG-6 and AG-12, are listed in Table 2. Mycorrhizal isolates of $R$. solani were selected from an inventory of isolates collected from mature $P$. acuminata plants at 10 bush sites in New South Wales (23; E. J. Pope, unpublished data). One site was at Windsor, $50 \mathrm{~km}$ northwest of Sydney, and the others, including Bligh Park, Beecroft, Cheltenham, Glenbrook, and Mellong, were in the Sydney region. Sites were chosen because of the known presence of $P$. acuminata. At the Windsor site, in addition to recovery from mature plants, isolates of $R$. solani were recovered from protocorms that developed from seeds of $P$. acuminata that had been buried in $80-\mu \mathrm{m}$-pore-size Millipore filter envelopes. Isolates were also collected from leaf litter adjacent to $P$. acuminata plants but, as distance from the plants increased, recovery of $R$. solani decreased. Repeated attempts also were made to recover $R$. solani from mineral soil at the Windsor site, but all failed. Specific recovery methods and media are enumerated by Perkins and McGee (23). Healthy fungal coils were removed from colonized orchid tissues and cultured according to the method of Warcup and Talbot (28). All mycorrhizal $P$. acuminata adult plants and protocorms were colonized only by multinucleate Rhizoctonia (23).

Isolate characterization. AG determinations were made according to a modification of the method of Parmeter et al. (6,22). Anastomosis reactions were grouped into categories in which category 0 (C0) is no reaction and $\mathrm{C} 3$ is a clonal reaction, the equivalent of self anastomosis (6). Also, to assess diversity within the AG, isolates of AG-12 were paired with each other in all possible combinations.

Attempts were made to induce 18 isolates of AG-12 to sporulate on $1.5 \%$ water agar, $2 \% \mathrm{~V} 8$ juice agar (18 $\mathrm{g}$ of agar plus $20 \mathrm{ml}$ of V8 juice per liter) and with the Ogoshi's (20) soil-overlay tech- 
nique. Each of the three methods was run twice using three petri plates of each isolate per run.

To study cultural characteristics, isolates of AG-12 were grown on potato dextrose agar (PDA) at 20 to $21^{\circ} \mathrm{C}$ in the dark. Three petri plates of each isolate were grown in each of two runs. Each time, observations of cultural characteristics were made over a 3-week period.

Hyphal diameter and the number of nuclei per cell were determined on cultures grown at 20 to $23^{\circ} \mathrm{C}$ on cellophane overlaying $1.5 \%$ water agar in petri plates. Mycelium was stained with $3 \% \mathrm{KOH}$ and safranin $\mathrm{O}(5)$ and examined with bright field optics at $\times 400$. Three petri plates of each isolate were grown for each of two runs. Hyphal diameter was determined on each of three isolates by measuring 20 cells per isolate at right angles to the longitudinal cell wall. Nuclei were counted in 20 cells per isolate selected from a location in the stain gradient where nuclei and septa could be clearly observed.

Radial growth of seven selected isolates of AG-12 was determined by growing them on PDA at $25^{\circ} \mathrm{C}$ in the dark. Radial growth was measured at 24 and $72 \mathrm{~h}$ after inoculation. One isolate each of AG-1, AG-2, AG-3, and AG-4 were included for comparison. Each treatment was replicated three times, and the experiment was repeated once.

Determinations of pathogenic potential. Pathogenic potential of selected isolates of AG-12, as well as selected mycorrhizal iso- lates of AG-6, was determined on radish (Raphanus sativus L.), cauliflower (Brassica oleracea L. var. botrytis L.), head lettuce (Lactuca sativa L.), barley (Hordeum vulgare L.), and potato (Solanum tuberosum L.). Virulence on potato (cv. Russet Burbank) was determined at $10^{\circ} \mathrm{C}$ on developing sprouts and roots according to a method described by Carling and Leiner (7). Virulence on the other four host species was determined on germinating seeds on $2 \%$ water agar in petri dishes $(100 \times 15 \mathrm{~mm})$. Each dish was seeded in the center with a PDA disk ( $7 \mathrm{~mm}$ in diameter) of the appropriate fungal isolate. Sterile PDA disks were used to seed the control treatments. Two days after seeding the petri dishes with the various fungus treatments, 18 surface-sterilized $(0.5 \% \mathrm{NaClO}$ for $1 \mathrm{~min}$ ) seeds (six seeds per dish) were evenly spaced on the agar surface in a circle halfway between the center and the edge of the dish. The growing fungal colonies reached the seeds just as they began to germinate. Stacks of dishes were placed in plastic boxes in a growth chamber in the dark at $21^{\circ} \mathrm{C}$. Notes on damage to developing seedlings were taken at 3 and 8 days after placement of the seeds on the agar. Damage assessments included the following scale: $0=$ no damage, $1=$ minor discoloration of hypocotyl; 2 = discoloration plus small $(<1 \mathrm{~mm}$ in diameter $)$ necrotic lesions on stem, hypocotyl, or root; $3=$ discoloration plus large $(1 \mathrm{~mm}$ in diameter) necrotic lesions on stem, hypocotyl, or root; and $4=$ seedling dead. All experiments designed to determine pathogenic potential were repeated once.

TABLE 1. Tester isolates representing the 12 established anastomosis groups (AGs) of Rhizoctonia solani used to determine the AG identity of AG-12

\begin{tabular}{|c|c|c|c|c|c|}
\hline $\mathrm{AG}$ & Subgroup & Isolate & Origin & Host & Collector or supplier \\
\hline 1 & IA & CSKa & Japan & Oryza sativa & S. Kuninaga \\
\hline 1 & IB & SFBV-1 & Japan & Beta vulgaris & S. Kuninaga \\
\hline 1 & $\mathrm{IC}$ & M43 & Quebec, Canada & Pinus resinosa & N. A. Anderson \\
\hline 2 & 1 & F56L & Alaska, United States & Solanum tuberosum & D. E. Carling \\
\hline 2 & 1 & 457 & Japan & Unknown & E. E. Butler \\
\hline 2 & 2IIIB & C330 & Japan & Oryza sativa & A. Ogoshi \\
\hline 2 & 2IIIB & $\mathrm{B} 60 \mathrm{~K}$ & Japan & Beta vulgaris & S. Kuninaga \\
\hline 2 & $2 \mathrm{IV}$ & RI64 & Japan & Beta vulgaris & A. Ogoshi \\
\hline 2 & $2 \mathrm{IV}$ & RH16 & Japan & Beta vulgaris & S. Kuninaga \\
\hline 3 & $\mathrm{P}$ & ST-11-6 & Japan & Solanum tuberosum & A. Ogoshi \\
\hline 3 & $\mathrm{P}$ & SCL24 & Alaska, United States & Solanum tuberosum & D. E. Carling \\
\hline 3 & $\mathrm{~T}$ & 263 & Georgia, United States & Nicotiana tabacum & A. Csinos \\
\hline 4 & HG-I & $\mathrm{AH}-1$ & Japan & Arachis hypopaea & S. Kuninaga \\
\hline 4 & HG-II & RR5-2 & Japan & Beta vulgaris & S. Kuninaga \\
\hline 5 & $\ldots{ }^{\mathrm{y}}$ & ST-6-1 & Japan & Solanum tuberosum & A. Ogoshi \\
\hline 5 & $\ldots$ & Rh 184 & Japan & Beta vulgaris & S. Naito \\
\hline 6 & GV & NKN2-1 & Japan & Soil & S. Kuninaga \\
\hline 6 & HG-I & OHT1-1 & Japan & Soil & S. Kuninaga \\
\hline 6 & $?^{\mathrm{z}}$ & $\mathrm{CC} 1$ & New South Wales, Australia & Pterostylis acuminata & E. J. Pope \\
\hline 6 & HG-I & HAM1.1 & Japan & Soil & S. Kuninaga \\
\hline 7 & $\ldots$ & 1535 & Japan & Soil & S. Kuninaga \\
\hline 7 & $\ldots$ & 1556 & Japan & Soil & S. Kuninaga \\
\hline 7 & $\ldots$ & 91PT123-1A & Arkansas, United States & Soil & C. S. Rothrock \\
\hline 7 & $\ldots$ & 91ST8057-2A & Arkansas, United States & Soil & C. S. Rothrock \\
\hline 7 & $\ldots$ & 91ST8112-9A & Arkansas, United States & Soil & C. S. Rothrock \\
\hline 8 & ZG1-1 & 89570 & Western Australia, Australia & Hordeum vulgare & G. C. MacNish \\
\hline 8 & ZG1-1 & 91784 & Western Australia, Australia & Lupinus angustifolius & G. C. MacNish \\
\hline 8 & ZG1-2 & 90812 & Western Australia, Australia & Lupinus angustifolius & G. C. MacNish \\
\hline 8 & ZG1-2 & SA50 & Southern Australia, Australia & Avena sativa & A. Dube \\
\hline 8 & ZG1-3 & SA1512 & Southern Australia, Australia & Hordeum vulgare & S. M. Neate \\
\hline 8 & ZG1-4 & 88351 & Western Australia, Australia & Hordeum vulgare & G. C. MacNish \\
\hline 8 & ZG1-4 & 91006 & Western Australia, Australia & Hordeum vulgare & G. C. MacNish \\
\hline 8 & ZG1-5 & 91623 & Western Australia, Australia & Hordeum vulgare & G. C. MacNish \\
\hline 8 & ZG1-5 & 92547 & Western Australia, Australia & Hordeum vulgare & G. C. MacNish \\
\hline 9 & $\mathrm{TP}$ & V12M & Alaska, United States & Solanum tuberosum & D. E. Carling \\
\hline 9 & TX & S9R1 & Alaska, United States & Soil & D. E. Carling \\
\hline 10 & $\ldots$ & W395 & Washington, United States & Triticum aestivum & A. Ogoshi \\
\hline 10 & $\ldots$ & W3751 & Washington, United States & Triticum aesitvum & A. Ogoshi \\
\hline 11 & $\ldots$ & $\mathrm{R} 1352$ & Western Australia, Australia & Lupinus augustifolius & M. W. Sweetingham \\
\hline 11 & $\ldots$ & ROTH26 & Arkansas, United States & Oryza sativa & C. S. Rothrock \\
\hline $\mathrm{BI}$ & $\ldots$ & AI 1-4 & Japan & Soil & S. Kuninaga \\
\hline $\mathrm{BI}$ & $\ldots$ & TE 2-4 & Japan & Soil & S. Kuninaga \\
\hline
\end{tabular}

x Each isolate in this list was paired with $R$. solani AG-12 isolates W1, PR.1, and SWd. All pairings gave the C0 anastomosis reaction.

y Subgroups either do not exist or have not been formally designated.

z Subgroup identity not known. 


\section{RESULTS}

Anastomosis reactions. Three representative isolates of AG-12 (PR-1, SWd, and W1) were paired with two or more tester isolates representing each of the 12 known AGs of $R$. solani (Table 1). Whenever possible, subgroups of AGs were also represented by two testers; thus, a total of 42 tester isolates was included. All three isolates of AG-12 gave $\mathrm{C} 0$ reactions with each of the 42 testers (Table 1).

Anastomosis reactions between pairs of isolates within AG-12 were also examined. Pairing of the original 20 isolates of AG-12 in all possible combinations revealed that two pairs of isolates gave C3 anastomosis reactions: WD2 with WDa and SWa with SWd. The remaining 18 isolates gave $\mathrm{C} 2$ anastomosis reactions with each other in all possible combinations.

Isolate characterization. Despite repeated attempts, none of the isolates of AG-12 produced hymenia or basidiospores on $1.5 \%$ water agar, $2 \% \mathrm{~V} 8$ juice agar or on soil-overlay plates.

All tested isolates of AG-12 were light tan when young, and some had streaks of white radiating out from the center of the culture. As the cultures aged, their color darkened and most were very dark brown when mature. Concentric rings formed on most cultures and, by 5 days after inoculation, sclerotia often formed in the darkened rings. In some isolates, sclerotia were randomly scattered over the surface of the colony. Sclerotia 0.5 to $1.5 \mathrm{~mm}$ in diameter were tan when young and generally became dark brown when mature. Large sclerotia were not observed, although individual sclerotia sometimes coalesced to form clumps. Aerial mycelium was common in all young cultures, but mycelia became increasingly appressed as the cultures aged. Some isolates remained floccose throughout the growing cycle.

The average hyphal diameter of isolates B1, PR.1, and H.1 was 6.7 (range 5.4 to 7.7 ), 7.6 (range 6.2 to 9.2 ), and $7.7 \mu \mathrm{m}$ (range 6.9 to

TABLE 2. Isolates of Rhizoctonia solani used in teleomorph determination, pathogenicity, and other characterization studies ${ }^{\mathrm{x}}$

\begin{tabular}{|c|c|c|c|c|}
\hline $\mathrm{AG}^{\mathrm{y}}$ & Isolate & Origin & Host & $\begin{array}{l}\text { Collector } \\
\text { or supplier }\end{array}$ \\
\hline 2 & KAB-1 & Alaska, United States & Daucus carota & D. E. Carling \\
\hline 3 & L32 & Alaska, United States & Solanum tuberosum & D. E. Carling \\
\hline 3 & M26 & Alaska, United States & Solanum tuberosum & D. E. Carling \\
\hline 6 & AT2-1 & Japan & Soil & S. Kuninaga \\
\hline 6 & ATi & South Africa & Acacia tortilis $^{\mathrm{Z}}$ & L. Meyer \\
\hline 6 & RS1044 & South Africa & Triticum aestivum & L. Meyer \\
\hline 6 & RSTK18 & Tanzania & Triticum aestivum & L. Meyer \\
\hline 6 & $\mathrm{SPb}$ & New South Wales, Australia & Leaf litter & E. Pope \\
\hline 6 & $\mathrm{WDb}$ & New South Wales, Australia & Leaf litter & E. Pope \\
\hline 12 & B1 & New South Wales, Australia & Pterostylis acuminata & A. Perkins \\
\hline 12 & G3 & New South Wales, Australia & Pterostylis acuminata & E. Pope \\
\hline 12 & G4 & New South Wales, Australia & Pterostylis acuminata & E. Pope \\
\hline 12 & G6 & New South Wales, Australia & Pterostylis acuminata & E. Pope \\
\hline 12 & H1 & New South Wales, Australia & Pterostylis acuminata & A. Perkins \\
\hline 12 & PR-1 & New South Wales, Australia & Pterostylis acuminata & A. Perkins \\
\hline 12 & $\mathrm{SPc}$ & New South Wales, Australia & Leaf litter & E. Pope \\
\hline 12 & SP1 & New South Wales, Australia & Pterostylis acuminata & A. Perkins \\
\hline 12 & SP2 & New South Wales, Australia & Pterostylis acuminata & E. Pope \\
\hline 12 & SP3 & New South Wales, Australia & Pterostylis acuminata & E. Pope \\
\hline 12 & SWa & New South Wales, Australia & Leaf litter & E. Pope \\
\hline 12 & SWd & New South Wales, Australia & Leaf litter & E. Pope \\
\hline 12 & SW1 & New South Wales, Australia & Pterostylis acuminata & E. Pope \\
\hline 12 & W1 & New South Wales, Australia & Pterostylis acuminata & E. Pope \\
\hline 12 & $\mathrm{~W} 2$ & New South Wales, Australia & Pterostylis acuminata & E. Pope \\
\hline 12 & W3 & New South Wales, Australia & Pterostylis acuminata & A. Perkins \\
\hline 12 & WDa & New South Wales, Australia & Leaf litter & E. Pope \\
\hline 12 & WD2 & New South Wales, Australia & Pterostylis acuminata & E. Pope \\
\hline 12 & WD3 & New South Wales, Australia & Pterostylis acuminata & E. Pope \\
\hline 12 & WD6 & New South Wales, Australia & Pterostylis acuminata & E. Pope \\
\hline
\end{tabular}

${ }^{x}$ Isolates M43, RI64, SCL24, AH1, NKN2-1, HAM1-1, and CC1 also were used in some of the characterization studies.

y $\mathrm{AG}=$ anastomosis group.

${ }^{\mathrm{z}}$ Umbrella-thorn $=$ Acacia tortilis (Forsk.) Hayne subsp. Heteracantha (Burch) Brenan.
8.5), respectively, and the average number of nuclei per cell for the same three isolates was 4.1 (range 3 to 5), 3.4 (range 3 to 4), and 3.7 (range 2 to 5 ).

After 24 and $72 \mathrm{~h}$, the mean radial growth of the seven isolates of AG-12 was 25 (range 22 to 30) and $77 \mathrm{~mm}$ (range 69 to 84), respectively. The radial growth of the four control isolates was $26 \mathrm{~mm}$ (range 24 to 27 ) after $24 \mathrm{~h}$ and $81 \mathrm{~mm}$ (range 78 to 85 ) after $72 \mathrm{~h}$.

Determinations of pathogenic potential. Under conditions of this study, shoot and root tissues of potato seedlings were virtually undamaged by isolates of AG-12 or by mycorrhizal or other isolates of AG-6 (Table 3). This is in contrast to the heavy damage caused on both shoot and root tissues by isolates of the potato subgroup of AG-3. Similarly, little damage to lettuce seedlings was observed in response to inoculation with isolates of AG-12 and AG-6 (Table 4), although AG-12 did cause discoloration and limited tissue necrosis to $41 \%$ of the seedlings by 8 days after inoculation. However, cauliflower seedlings (Table 5) were moderately to heavily damaged by all mycorrhizal isolates of AG-6 and AG-12 tested, and damage was evident by 3 days after inoculation. Extent and time of damage development in radish was similar to that observed in cauliflower (data not shown), and damage to barley was limited and highly variable (data not shown).

\section{DISCUSSION}

Isolates of $R$. solani AG-12 collected from protocorms and adult plants of $P$. acuminata, as well as from leaf litter adjacent to $P$. acuminata plants, were originally reported to belong to AG-6 (23). In this study, which included additional isolates collected from adult plants and leaf litter, we found that 3 of the 23 selected isolates of $R$. solani were members of AG-6, but the remaining 20 were all members of a previously undescribed group that we now propose to designate AG-12. All tester isolates listed in Table 1, representing the known AGs and most AG subgroups, gave the $\mathrm{C} 0$ anastomosis reaction with each of the three selected testers of AG-12. The absence of the $\mathrm{C} 1$ (bridging) anastomosis reaction adds AG-12 to the existing list of AGs (i.e., AG-1, AG-4, AG-5, AG-7, AG-9, and AG-10) that do not bridge with other AGs of $R$. solani (6). The lack of a bridging reaction is an indication of the degree of isolation of AG-12 within the $R$. solani complex.

Of the original 20 isolates of AG-12, two pairs gave $\mathrm{C} 3$ anastomosis reactions with each other. In both cases, the pairs giving the $\mathrm{C} 3$ reaction had been collected at the same specific geographical site (23). In one of these cases (SWa-SWd), both isolates were collected from leaf litter, whereas, in the other case (WD2-WDa), one member of the clonal pair was collected from a $P$. acuminata plant and the other from adjacent leaf litter. A physical connection between the pair of clonal isolates recovered from plant and leaf litter is implied because isolates were not recoverable from leaf litter in areas where $P$. acuminata plants were not growing. Addi-

TABLE 3. Damage to shoots and roots of germinating potato seed pieces caused by isolates of Rhizoctonia solani

\begin{tabular}{lccl}
\hline & & \multicolumn{2}{c}{ Damage scale $^{\mathrm{y}}$} \\
\cline { 3 - 4 } AG $^{\mathrm{x}}$ & No. of isolates & Shoot & Root \\
\hline Control & $\ldots$ & $0.0 \mathrm{a}^{\mathrm{z}}$ & $0.0 \mathrm{a}$ \\
AG-3 & 3 & $2.5 \mathrm{~b}$ & $2.6 \mathrm{~b}$ \\
AG-6 (J) & 3 & $0.1 \mathrm{a}$ & $0.1 \mathrm{a}$ \\
AG-6 (A) & 3 & $0.3 \mathrm{a}$ & $0.3 \mathrm{a}$ \\
AG-6 (S) & 3 & $0.3 \mathrm{a}$ & $0.3 \mathrm{a}$ \\
AG-12 & 3 & $0.1 \mathrm{a}$ & $0.2 \mathrm{a}$ \\
\hline
\end{tabular}

${ }^{\mathrm{x}} \mathrm{AG}=$ anastomosis group. Isolates of AG-6 from Japan (J), Southern Africa (A), and Australia (S).

y Damage assessed on a scale ranging from 0 to 4 , in which $0=$ no damage and $4=$ all shoots and roots dead. The experiment was run twice with similar results in both runs. Numbers are means of five replicates from the second run. ${ }^{\mathrm{z}}$ Numbers in columns followed by the same letter are not significantly different, Kruskal-Wallis $(P=0.05)$. 
tionally, the detection of 18 different vegetative compatibility populations (16) among the 20 evaluated isolates of AG-12 illustrates that a level of diversity exists within the population despite what currently seems to be a limited geographical distribution (Sydney, Australia) and a very limited range of orchid host species $(P$. acuminata). In a study of isolates of AG-12 using random amplified polymorphic DNA analysis (E. J. Pope, unpublished data), a high level of diversity also was detected.

Several authors $(12,28,31)$ report production of a Thanatephorus teleomorph by isolates of Rhizoctonia collected from mycorrhizal orchids. We have acquired three of these isolates from the University of Alberta Microfungus Collection and Herbarium (UAMH), including two isolates of T. pennatus $(25,31)$ and one of $T$. сисиmeris (31). Preliminary anastomosis tests with the T. pennatus isolates (UAMH 5404 and UAMH 5724) have been inconclusive, but the isolate of T. cucumeris (UAMH 7552) does not anastomose (C0) with tester isolates of AG-12. We know, therefore, that UAMH 7552 is not from AG-12, but further study will be required to establish its relationship, as well as that of UAMH 5404 and UAMH 5724, to all other AGs of $R$. solani.

Data on hyphal diameter, number of nuclei per cell, and radial growth puts AG-12 within the range reported previously for $R$. solani $(8,20)$. However, failure to induce the $T$. cucumeris stage to form in any of the tested isolates of AG-12 by any of the methods used leaves us without this important confirmation of taxonomic identity. It is well known that a large percentage of isolates of all AGs of $R$. solani cannot be induced to form basidiospores in culture with any of the methods currently available (2). An extreme example of this is isolates of the potato subgroup of AG-3, a subgroup that most believe has not produced basidiospores in culture. On the other hand, isolates of the potato subgroup of AG-3 can produce basidiospores prolifically in natural settings under cool, humid conditions. Basidiospore production in the field by mycorrhizal isolates of AG-6 and AG-12 has not been reported.

Isolates of $R$. solani AG-12 and AG-6 appear to be the only fungi that establish a mycorrhizal relationship with $P$. acuminata (23). Although binucleate Rhizoctonia and other mycorrhizal species were present in the sampling areas, none were found in mycorrhizal association with $P$. acuminata. Most members of the genus Rhizoctonia that are mycorrhizal with orchids are binucleate, although some isolates of $R$. solani have been recovered from naturally colonized mycorrhizal plants $(12,24,28,29,31)$. Multiple isolates representing many different AGs of $R$. solani have been shown to induce symbiotic germination and protocorm formation by various orchids, but there are indications that specificity between host and fungus may be lacking at this early stage of development (17, 30,31 ). Typical mycorrhizal hyphal coils formed in protocorm tis-

TABLE 4. Observed damage to germinating lettuce seedlings caused by several isolates of Rhizoctonia solani ${ }^{\mathrm{w}}$

\begin{tabular}{lcccccccc}
\hline & \multirow{2}{*}{$\begin{array}{c}\text { No. of } \\
\text { isolate }\end{array}$} & \multicolumn{3}{c}{3 days after inoculation } & & \multicolumn{3}{c}{8 days after inoculation } \\
\cline { 8 - 9 } \cline { 7 - 8 } AG $^{\mathrm{n}}$ & None & Medium $^{\mathrm{y}}$ & Dead & & None & Medium & Dead \\
\hline$\ldots$ & $\ldots$ & $17^{\mathrm{z}}$ & 0 & 0 & 18 & 0 & 0 \\
1 & 1 & 17 & 0 & 0 & 17 & 0 & 0 \\
$2-1$ & 1 & 17 & 1 & 0 & 17 & 0 & 1 \\
$2-2$ & 1 & 18 & 0 & 0 & 18 & 0 & 0 \\
3 & 1 & 18 & 0 & 0 & 18 & 0 & 0 \\
4 & 1 & 1 & 5 & 12 & 0 & 5 & 13 \\
$6(\mathrm{~J})$ & 3 & 18 & 0 & 0 & 18 & 0 & 0 \\
$6(\mathrm{~A})$ & 3 & 17 & 0 & 0 & 17 & 0 & 0 \\
$6(\mathrm{~S})$ & 3 & 15 & 1 & 0 & 14 & 2 & 2 \\
12 & 3 & 17 & 1 & 0 & 11 & 7 & 0 \\
\hline
\end{tabular}

${ }^{\mathrm{w}}$ Experiment run twice with similar results. Data shown are from the second run.

${ }^{\mathrm{x}} \mathrm{AG}=$ anastomosis group. Isolates of AG-6 from Japan (J), Southern Africa (A), and Sydney, Australia (S).

${ }^{\mathrm{y}}$ Medium $=$ medium damage; tissue discoloration and necrosis starting at hypocotyl and sometimes extending down the root or up the stem.

${ }^{\mathrm{z}}$ Number indicates the number of seedlings exhibiting each symptom. sues in these studies, but protocorm colonization, especially that created in the laboratory, does not necessarily indicate the existence of such relationships in nature (17). Furthermore, a mycorrhizal relationship at the protocorm stage does not necessarily translate to a mycorrhizal relationship with the mature plant.

Perkins and McGee (23), and later E. J. Pope (unpublished data), isolated AG-6 and what we now know to be AG-12 from leaf litter at varying distances from mycorrhizal $P$. acuminata plants. Perkins and McGee (23) reported that the likelihood of recovery from leaf litter decreased as the distance from the mycorrhizal plants increased, until recovery was no longer successful. This suggests that, in the environments of their collection, mycorrhizal isolates of AG-6 and AG-12 may not be competitive enough to survive (saprophytically) in the absence of a host plant. Like all other isolates of $R$. solani, mycorrhizal isolates of AG-6 and AG-12 are easily grown in vitro. Nevertheless, a mycorrhizal host may be required if they are to survive in nature.

Although this is the initial report of AG-12, AG-6 has previously been found at many locations in Japan (15), South Africa and Tanzania (9), and the northwestern United States (18). Japanese isolates are described as nonpathogens (15), but more recent reports associate isolates of AG-6 with crater disease of wheat (9) and apple replant disease (18). It is not known if isolates of AG-6 collected at locations other than the vicinity of Sydney, Australia, can establish mycorrhizal relationships with $P$. acuminata or other orchids. Also unknown is the pathogenic capability of mycorrhizal isolates of AG-6 and AG-12 in natural systems.

Damage caused by mycorrhizal isolates of AG-12 and AG-6 was assessed on five plant species in this study. Although methods used for these tests are artificial and highly favorable to the fungus, the results do give some indication of pathogenic potential. We anticipated seeing little or no damage in response to inoculation with the mycorrhizal isolates of AG-12 or AG-6, and very little damage was observed on potato and barley seedlings. A potential for damage by both mycorrhizal AGs to lettuce seedlings is suggested, and the potential damage to cauliflower and radish is even more strongly suggested. In spite of these suggested potentials, it will be necessary to evaluate these and other isolates under field conditions before drawing any firm conclusions regarding virulence.

We know of no evidence prior to this article that shows that mycorrhizal isolates of $R$. solani are capable of damaging plants. Several investigators $(13,17,27,30)$ report that pathogenic isolates of $R$. solani establish mycorrhizal relationships with protocorms of Dactylorhiza purpurella (T. and T.A. Steph.) Soo and other orchids. In each of these cases, however, the pathogenic isolates of $R$. solani had not been collected initially from naturally colonized orchid plants but rather from diseased plants of other species or from

TABLE 5. Observed damage to germinating cauliflower seedlings caused by various isolates of Rhizoctonia solani ${ }^{\mathrm{w}}$

\begin{tabular}{|c|c|c|c|c|c|c|c|}
\hline \multirow[b]{2}{*}{$\mathrm{AG}^{\mathrm{x}}$} & \multirow{2}{*}{$\begin{array}{l}\text { No. of } \\
\text { isolates }\end{array}$} & \multicolumn{3}{|c|}{3 days after inoculation } & \multicolumn{3}{|c|}{8 days after inoculation } \\
\hline & & None & Medium $^{y}$ & Dead & None & Medium & Dead \\
\hline$\ldots$ & $\ldots$ & $17^{z}$ & 0 & 0 & 17 & 0 & 0 \\
\hline 1 & 1 & 0 & 18 & 0 & 0 & 0 & 18 \\
\hline $2-1$ & 1 & 0 & 16 & 0 & 0 & 0 & 16 \\
\hline $2-2$ & 1 & 0 & 18 & 0 & 0 & 18 & 0 \\
\hline 3 & 1 & 15 & 3 & 0 & 0 & 18 & 0 \\
\hline 4 & 1 & 0 & 2 & 16 & 0 & 0 & 18 \\
\hline $6(\mathrm{~J})$ & 3 & 12 & 5 & 0 & 6 & 12 & 0 \\
\hline 6 (A) & 3 & 15 & 2 & 0 & 11 & 6 & 0 \\
\hline $6(S)$ & 3 & 0 & 17 & 1 & 0 & 13 & 5 \\
\hline 12 & 3 & 10 & 8 & 0 & 0 & 17 & 1 \\
\hline
\end{tabular}

${ }^{w}$ Experiment run twice with similar results. Data shown are from the second run.

x $\mathrm{AG}=$ anastomosis group. Isolates of AG-6 from Japan (J), Southern Africa (A), and Sydney, Australia (S).

${ }^{\mathrm{y}}$ Medium = medium damage; tissue discoloration and necrosis starting at hypocotyl and sometimes extending down the root or up the stem.

${ }^{\mathrm{z}}$ Number indicates the number of seedlings exhibiting each symptom. 
soil. Thus, it can be argued that these isolates may not legitimately be called mycorrhizal.

This research records the existence of $R$. solani AG-12 and expands upon existing information about isolates of $R$. solani that are mycorrhizal with orchids. Additional research with $P$. acuminata and $R$. solani, as well as other orchids and mycorrhizal fungi, will provide needed answers to questions relating to pathogenicity in mycorrhizal fungi and specificity between plant and fungus in mycorrhizal systems. Representative isolates of mycorrhizal AG12 (W1, PR-1, and SWd) and AG-6 (CC1, SPb and, WDb) have been sent to the American Type Culture Collection.

\section{ACKNOWLEDGMENTS}

We thank A. J. Perkins and P. A. McGee for providing some of the isolates of AG-6 and AG-12 used in this study.

\section{LITERATURE CITED}

1. Adams, Jr., G. C. 1988. Thanatephorus cucumeris (Rhizoctonia solani): A species complex of wide host range. Adv. Plant Pathol. 6:535-552.

2. Adams, Jr., G. C., and Butler, E. E. 1983. Environmental factors influencing the formation of basidia and basidiospores in Thanatephorus $\mathrm{cu}$ cumeris. Phytopathology 73:152-155.

3. Anderson, N. A. 1982. The genetics and pathology of Rhizoctonia solani. Annu. Rev. Phytopathol. 20:329-347.

4. Anderson, T. F., and Rasmussen, H. N. 1996. The mycorrhizal species of Rhizoctonia. Pages 379-390 in: Rhizoctonia Species: Taxonomy, Molecular Biology, Ecology, Pathology, and Disease Control. B. Sneh, S. Jabaji-Hare, S. Neate, and G. Dijst, eds. Kluwer Academic Publishers, Dordrecht, the Netherlands.

5. Bandoni, R. J. 1971. Safranin-O as a rapid nuclear stain for fungi. Mycologia 63:873-874

6. Carling, D. E. 1996. Grouping in Rhizoctonia solani by hyphal anastomosis. Pages 37-47 in: Rhizoctonia Species: Taxonomy, Molecular Biology, Ecology, Pathology, and Disease Control. B. Sneh, S. Jabaji-Hare, S. Neate, and G. Dijst, eds. Kluwer Academic Publishers, Dordrecht, the Netherlands.

7. Carling, D. E., and Leiner, R. H. 1986. Isolation and characterization of Rhizoctonia solani and binucleate $R$. solani-like fungi from aerial stems and subterranean organs of potato plants. Phytopathology 76:725-729.

8. Carling, D. E., Leiner, R. H., and Kebler, K. M. 1987. Characterization of a new anastomosis group (AG-9) of Rhizoctonia solani. Phytopathology 77:1609-1612.

9. Carling, D. E., Meyer, L., and Brainard, K. A. 1996. Crater disease of wheat caused by Rhizoctonia solani AG-6. Plant Dis. 80:1429.

10. Carling, D. E., Rothrock, C. S., MacNish, G. C., Sweetingham, M. W., Brainard, K. A., and Winters, S. W. 1994. Characterization of anastomosis group 11 (AG-11) of Rhizoctonia solani. Phytopathology 84:1387-1393.

11. Cubeta, M. A., and Vilgalys, R. 1997. Population biology of the Rhizoctonia solani complex. Phytopathology 87:480-484.

12. Currah, R. S. 1987. Thanatephorus pennatus sp. nov. isolated from my- corrhizal roots of Calypso bulbosa (Orchidaceae) from Alberta. Can. J. Bot. 65:1957-1960.

13. Downie, D. G. 1959. The mycorrhiza of Orchis purpurella. Trans. Bot. Soc. Edinburgh 38:16-29.

14. Kuninaga, S., Natsuaki, T., Takeuchi, T., and Yokosawa, R. 1997. Sequence variation of the rDNA ITS regions within and between anastomosis groups in Rhizoctonia solani. Curr. Genet. 32:237-243.

15. Kuninaga, S., Yokosawa, R., and Ogoshi, A. 1979. Some properties of anastomosis group 6 and BI in Rhizoctonia solani Kühn. Ann. Phytopathol. Soc. Jpn. 45:207-214.

16. MacNish, G. C., Carling, D. E., and Brainard, K. A. 1996. Relationship of microscopic and macroscopic vegetative reactions in Rhizoctonia solani and the occurrence of vegetatively compatible populations (VCP) in AG-8. Mycol. Res. 100:61-68.

17. Masuhara, G., Katsuya, K., and Yamaguchi, K. 1993. Potential for symbiosis of Rhizoctonia with seeds of Spiranthes sinensis var. amoena in vitro. Mycol. Res. 97:746-752.

18. Mazzola, M. 1997. Identification and pathogenicity of Rhizoctonia spp. isolated from apple roots and orchard soils. Phytopathology 87:582-587.

19. Moore, R. T. 1987. The genera of Rhizoctonia-like fungi: Aschorhizoctonia, Ceratorhiza gen. nov., Epulorhiza gen. nov., Moniliopsis, and Rhizoctonia. Mycotaxon 29:91-99.

20. Ogoshi, A. 1976. Studies on the grouping of Rhizoctonia solani Kühn with hyphal anastomosis, and on the perfect stage of groups. Bull. Ser. C No. 3. Natl. Inst. Agric. Sci., Tokyo.

21. Ogoshi, A. 1987. Ecology and pathogenicity of anastomosis and intraspecific groups of Rhizoctonia solani Kühn. Annu. Rev. Phytopathol. 25: 125-143.

22. Parmeter, J. R., Sherwood, M. W., and Platt, W. D. 1969. Anastomosis grouping among isolates of Thanatephorus cucumeris. Phytopathology 59:1270-1278

23. Perkins, A. J., and McGee, P. A. 1995. Distribution of the orchid mycorrhizal fungus, Rhizoctonia solani, in relation to its host, Pterostylis acuminata, in the field. Aust. J. Bot. 43:565-575.

24. Ramsey, R. R., Sivasithamparam, K., and Dixon, K. W. 1987. Anastomosis groups among Rhizoctonia-like endophytic fungi in southwestern Australian Pterostylis species (Orchidaceae). Lindleyana 2:161-166.

25. Roberts, P. 1998. Thanatephorus ochraceus: A saprophytic and orchid endomycorrhizal species. Sydowia 50:252-256.

26. Sneh, B., Burpee, L., and Ogoshi, A. 1991. Identification of Rhizoctonia species. The American Phytopathological Society, St. Paul, MN.

27. Warcup, J. H. 1985. Pathogenic Rhizoctonia and orchids. Pages 69-70 in: Ecology and Management of Soilborne Plant Pathogens. C. A. Parker, A. D. Rovira, K. J. Moore, P. T. W. Wong, and J. F. Kollmorgen, eds. The American Phytopathological Society, St. Paul, MN.

28. Warcup, J. H., and Talbot, P. H. B. 1967. Perfect state of rhizoctonias associated with orchids. New Phytol. 66:631-641.

29. Warcup, J. H., and Talbot, P. H. B. 1971. Perfect state of rhizoctonias associated with orchids II. New Phytol. 70:35-40.

30. Williamson, B., and Hadley, G. 1970. Penetration and infection of orchid protocorms by Thanatephorus cucumeris and other Rhizoctonia isolates. Phytopathology 60:1092-1096.

31. Zelmer, C. D., Cuthbertson, L., and Currah, R. S. 1996. Fungi associated with terrestrial orchid mycorrhizas, seeds, and protocorms. Mycoscience 37:439-448. 